\title{
Outcome of Titanium Elastic Intramedullary Nail in the Treatment of Shaft of Femur Fracture in Children. Khan JA, ${ }^{1}$ Singh GP, ${ }^{2}$ Pandey $A^{2}$
}

${ }^{1}$ Department of Orthopedics and Trauma Surgery

Karnali Academy of Health Sciences

Jumla, Nepal.

${ }^{2}$ Department of Orthopedics and Trauma Surgery

Universal College of Medical Sciences

Bhairhawa, Nepal.

\section{Corresponding Author}

Javed A Khan

Department of Orthopedics and Trauma Surgery

Karnali Academy of Health Sciences

Jumla, Nepal.

E-mail: drjaved123@yahoo.com

\section{Citation}

Khan JA, Singh GP, Pandey A. Outcome of Titanium Elastic Intramedullary Nail in the Treatment of Shaft of Femur Fracture in Children. Kathmandu Univ Med J 2015;51(3):195-9.

\begin{abstract}
Background

Femoral-shaft fractures are among the most common fractures of the lower extremity in children. There are several different options for treating femoral-shaft fractures in children. Elastic stable intramedullary nailing (ESIN) has become the standard treatment for fractures of shaft of femur in children for reasons including mini-invasive surgery, no need for casting, early mobilization and discharge as well as growing concerns toward cost-effectiveness.
\end{abstract}

\section{Objective}

To demonstrate the effectiveness of intramedullary fixation of fracture shaft of femur in skeletally immature children using the titanium elastic intramedullary nails.

\section{Method}

Forty children who underwent fixation with titanium intramedullary nails because of fracture of shaft of femur (Winquist and Hansen type 1 and 2) were reviewed. There were $60 \%$ male and $40 \%$ female patients and mean follow-up was six months. Time of union, deformity at fracture site, limb length discrepancy, knee range of motion and complications were assessed.

\section{Result}

Average age of the patients was 5.17 years (range 3 to 10). All patients achieved complete healing at a mean 12.8 weeks (range 10 to 20 weeks). Average limb length discrepancy was $-0.16 \mathrm{~cm}$ (range -1.0 to $1.1 \mathrm{~cm}$ ) average knee range of motion was 137.55 degrees (range 118 to 152 degrees). Complications were recorded in 13 (31.7\%) patients and included: Five malunion which did not show any deformity or functional impairment and eight superficial wound infections which were healed after removal of nail. All patients were active as their pre injury levels at six months follow up.

\section{Conclusion}

Elastic stable intramedullary nailing is the method of choice for the simple pediatrics fracture shaft of femur, as it is minimally invasive and shows good functional and cosmetic results. It allows short hospital stay and quick recovery from pain and is cast-free.

\section{KEY WORDS}

Children, fracture shaft of femur, titanium elastic nail (TEN). 


\section{INTRODUCTION}

Femoral-shaft fractures are among the most common fractures of the lower extremity in children, with an annual incidence of up to 1 per 5,000..$^{1,2}$ There are several different options for treating femoral-shaft fractures in children, including early or immediate application of a hip spica cast, skeletal or skin traction followed by spica cast, closed reduction and minimally invasive plate osteosynthesis, close reduction and, elastic intramedullary nailing, external fixation, plate fixation, and internal fixation with the insertion of intramedullary nails. ${ }^{3,4}$ Selecting the management strategy is dependent on factors such as the presence of other associated injuries or multiple trauma, fracture properties, age, and socioeconomic factors. Although initial traction followed by spica casting is traditionally used for femoral-shaft fractures in children, recent studies have shown its possible effects on social, economic, educational, and emotional costs. In contrast, elastic intramedullary nailing of femoral-shaft fractures has gained extensive popularity because of its better clinical and psycho-socioeconomic outcomes with lower risk of complications. ${ }^{5,6}$

Elastic stable intramedullary nailing (ESIN) has become the standard treatment for fractures of shaft of femur in children for reasons including mini-invasive surgery, no need for casting, early mobilization and discharge as well as growing concerns toward cost-effectiveness. The use of nails in children was pioneered in forearm fractures by Perez et al. 1977 and Firica et al. 1981.,8 But, the concept of two elastic intramedullary pins facing each other in a secant arc was developed and applied first to femur shaft fractures by the members of surgical staff from Nancy, France. ${ }^{9}$ Under their impulsion, ESIN was promoted worldwide. We aimed to report our early experience of ESIN in fracture shaft of femur in children with short term follow up focusing on complications, and treatment results.

\section{METHODS}

This prospective observational study was conducted from July 2011 to December 2012 in the Department of orthopedic and trauma Surgery of Universal Medical College Teaching Hospital, Bhairhawa, Nepal. Children 3-10 years of age or maximum weight up to $40 \mathrm{Kg}$ with simple femoral-shaft fractures (Winquist and Hansen Type I and II) participated in the study consecutively. Exclusion criteria were segmental, Winquist types III and IV comminuted fractures, previously diagnosed neuromuscular disease (e.g., cerebral palsy), metabolic bone disorders (e.g., osteomalacia), or pathological fractures, history of previous fracture or deformity in either limbs. Parents of all children gave informed consent prior to the study, which was authorized by the local scientific ethical committee. Surgery was performed with general anesthesia under the
C-arm image intensifier. After a linear incision of about 2 $\mathrm{cm}$, opening the fascia, and splitting the muscle fibers, a hole was opened in the distal femoral metaphysis about 2 $\mathrm{cm}$ proximal to distal femoral physis plate with a curved owl and enlarged. Then, each prebent titanium elastic nail was placed in retrograde through the distal part of the femur. Each nail was about $40 \%$ of the canal diameter at the narrowest site of the femoral shaft. Those cases where close reduction could not be achieved, open reduction were done through $2.5 \mathrm{~cm}$ anterolateral incision at the level of fracture. Nail was cut short to bury under the soft tissue. Wound was closed with sutures. Compression dressing was applied. All patients received second-generation cephalosporin prophylaxis, which was initiated just before the operation and continued 72 hours postoperatively. Knee bending exercises was started postoperatively as pain tolerated.

Patients were discharged after $3^{\text {rd }}$ post operative day with non weight bearing crutch walking and followed up in outpatient department. Follow-up visits were made at two weeks when sutures were removed, six weeks when wound infection and progress of union was observed in $x$ ray. At the same time patient was allowed to bear weight as tolerated. Then patient was followed up every fortnight to see progress of union. Nails were removed when union was achieved radiologically as well as clinically. Radiographs were reviewed for evidence of healing, defined as bridged femoral cortices (three or four of four cortices) on anteroposterior and lateral radiographs. ${ }^{10}$ Clinical union was considered when patient can walk comfortably without support. Limb alignment and limb length discrepancy were assessed immediate post operatively and at the final follow up when nails were removed. Measurements of angulations in the sagittal and coronal planes were done on anteroposterior and lateral radiographs that were made at the first post operative day and at the time of removal of the nail. Limb length discrepancy was also measured in comparison to normal limb. Range of knee motion, incision and skin infections were also assessed at each visit. After six months post operatively all parents were contacted by phone to find out any possible complications. The complications were classified as major or minor. Major complications were defined as conditions leading to unscheduled nail removal or operative treatment, including deep infection, implant irritation, or pain and nail breakage and mlunion and nonunion. ${ }^{11}$ Nonunion was defined as the absence of osseous union more than six months after the injury. ${ }^{12}$ Malunion was defined as an angulations of $>10$ degree in the coronal plane or $>15$ degree in the sagittal plane. Minor complications were defined as nail irritation or infection that was treated non operatively. ${ }^{11}$

Data were analyzed using SPSS software (windows version 16.0). 
Table 1. Master chart of $\mathbf{4 0}$ cases with their particulars and follow up findings

\begin{tabular}{|c|c|c|c|c|c|c|c|c|c|c|}
\hline \multirow[t]{2}{*}{ Case } & \multirow[t]{2}{*}{ Age } & \multirow[t]{2}{*}{ Sex } & \multirow[t]{2}{*}{ Wt. in Kg } & \multicolumn{2}{|c|}{$\begin{array}{l}\text { Angulation on Postoperative } \\
\text { Radiograph (degree) }\end{array}$} & \multicolumn{2}{|c|}{$\begin{array}{l}\text { Angulation on Final Radiograph } \\
\text { (degree) }\end{array}$} & \multirow[t]{2}{*}{$\begin{array}{l}\text { Knee ROM } \\
\text { (degree) }\end{array}$} & \multirow[t]{2}{*}{$\begin{array}{l}\text { Union } \\
\text { (weeks) }\end{array}$} & \multirow[t]{2}{*}{$\begin{array}{l}\text { Limb length } \\
\text { discrepancy }(\mathrm{mm})\end{array}$} \\
\hline & & & & Anteroposterior & Lateral & Anteroposterior & Lateral & & & \\
\hline 1 & 4 & M & 22 & Varus 1 & Ant 3 & Varus 3 & Ant 10 & 142 & 16 & 16 \\
\hline 2 & 3 & M & 20 & Varus 2 & Ant 6 & Varus 5 & Ant 8 & 138 & 10 & 10 \\
\hline 3 & 7 & $\mathrm{~F}$ & 27 & Valgus 5 & Ant 7 & Varus 4 & Ant 2 & 146 & 18 & 18 \\
\hline 4 & 5 & M & 28 & Varus 4 & Ant 2 & Varus 6 & Ant 7 & 128 & 14 & 14 \\
\hline 5 & 7 & $\mathrm{~F}$ & 30 & Varus 6 & Post 8 & Varus 9 & Post 18 & 122 & 18 & 18 \\
\hline 6 & 9 & M & 31 & Varus 5 & Ant 9 & Varus 10 & Ant 15 & 134 & 18 & 18 \\
\hline 7 & 5 & M & 29 & Varus 4 & Ant 2 & Varus 4 & Ant 11 & 140 & 16 & 16 \\
\hline 8 & 7 & M & 33 & Varus 6 & Post 7 & Varus 7 & Post 10 & 138 & 18 & 18 \\
\hline 9 & 7 & $\mathrm{~F}$ & 30 & Varus 7 & Ant 4 & Varus 10 & Ant 14 & 130 & 14 & 14 \\
\hline 10 & 10 & $\mathrm{~F}$ & 34 & Valgus 4 & Ant 10 & Valgus 6 & Ant 16 & 128 & 16 & 16 \\
\hline 11 & 4 & $M$ & 21 & Varus 1 & Ant 0 & Varus 4 & Ant 1 & 150 & 10 & 10 \\
\hline 12 & 7 & $\mathrm{~F}$ & 28 & Varus 3 & Ant 2 & Varus 5 & Ant 5 & 144 & 14 & 14 \\
\hline 13 & 8 & $\mathrm{~F}$ & 28 & Varus 2 & Ant 1 & Varus 6 & Ant 6 & 136 & 16 & 16 \\
\hline 14 & 9 & $M$ & 33 & Varus 5 & Ant 7 & Varus 7 & Ant 11 & 132 & 16 & 16 \\
\hline 15 & 7 & $M$ & 26 & Varus 5 & Post 6 & Varus 8 & Post 9 & 148 & 18 & 18 \\
\hline 16 & 3 & $M$ & 18 & Valgus 2 & Ant 3 & Valgus 5 & Ant 7 & 152 & 12 & 12 \\
\hline 17 & 6 & $\mathrm{~F}$ & 26 & Varus 3 & Ant 1 & Varus 7 & Ant 5 & 134 & 14 & 14 \\
\hline 18 & 6 & $M$ & 24 & Varus 2 & Post 5 & Varus 6 & Post 7 & 140 & 12 & 12 \\
\hline 19 & 8 & $M$ & 32 & Varus 4 & Ant 5 & Varus 7 & Ant 9 & 128 & 18 & 18 \\
\hline 20 & 3 & $\mathrm{~F}$ & 20 & Varus 4 & Ant 7 & Varus 3 & Ant 8 & 144 & 10 & 10 \\
\hline 21 & 6 & $M$ & 28 & Varus 2 & Ant 2 & Varus 7 & Ant 7 & 136 & 14 & 14 \\
\hline 22 & 8 & $\mathrm{~F}$ & 29 & Valgus 4 & Ant 6 & Valgus 9 & Ant 12 & 140 & 18 & 18 \\
\hline 23 & 4 & $M$ & 18 & Varus 1 & Post 4 & Varus 3 & Post 4 & 148 & 12 & 12 \\
\hline 24 & 6 & $M$ & 26 & Varus 2 & Ant 4 & Varus 5 & Ant 3 & 128 & 16 & 16 \\
\hline 25 & 3 & $M$ & 20 & Varus 2 & Post 1 & Varus 7 & Post 0 & 142 & 12 & 12 \\
\hline 26 & 10 & $\mathrm{~F}$ & 36 & Varus 7 & Ant 12 & Varus 16 & Ant 19 & 134 & 20 & 20 \\
\hline 27 & 5 & M & 25 & Varus 5 & Ant 4 & Varus 3 & Ant 8 & 140 & 16 & 16 \\
\hline 28 & 7 & $M$ & 28 & Valgus 5 & Ant 9 & Valgus 6 & Ant 11 & 130 & 18 & 18 \\
\hline 29 & 5 & $\mathrm{~F}$ & 24 & Varus 4 & Ant 3 & Varus 9 & Ant 10 & 142 & 12 & 12 \\
\hline 30 & 6 & $\mathrm{~F}$ & 30 & Varus 7 & Ant 7 & Varus 14 & Ant 16 & 122 & 16 & 16 \\
\hline 31 & 7 & $\mathrm{~F}$ & 33 & Varus 9 & Post 11 & Varus 10 & Post 18 & 136 & 18 & 18 \\
\hline 32 & 3 & $M$ & 19 & Varus 1 & Ant 2 & Varus 3 & Ant 2 & 150 & 10 & 10 \\
\hline 33 & 8 & $M$ & 36 & Valgus 4 & Ant 10 & Valgus 16 & Ant 10 & 134 & 18 & 18 \\
\hline 34 & 4 & $M$ & 26 & Varus 2 & Ant 0 & Varus 9 & Ant 7 & 146 & 14 & 14 \\
\hline 35 & 6 & $\mathrm{~F}$ & 28 & Varus 6 & Ant 11 & Varus 8 & Ant 10 & 144 & 16 & 16 \\
\hline 36 & 3 & $\mathrm{~F}$ & 20 & Varus 2 & Post 1 & Varus 4 & Post 8 & 138 & 14 & 14 \\
\hline 37 & 6 & $M$ & 24 & Varus 5 & Ant 7 & Varus 9 & Ant 7 & 140 & 16 & 16 \\
\hline 38 & 8 & $M$ & 32 & Varus 5 & Ant 3 & Varus 7 & Ant 14 & 134 & 14 & 14 \\
\hline 39 & 10 & $M$ & 36 & Varus 8 & Ant 10 & Varus 15 & Ant 11 & 118 & 20 & 20 \\
\hline 40 & 7 & $\mathrm{~F}$ & 33 & Valgus 8 & Post 13 & Valgus 18 & Post 10 & 146 & 16 & 16 \\
\hline
\end{tabular}

\section{RESULTS}

There were total 40 patients. Male patients were $60 \%$ and female were $40 \%$. Average age was 5.17 years ranging from 3 to 10 years. All fracture united with average time of 12.8 weeks ranging from 10 to 20 weeks. Average limb length discrepancy was -0.16 centimeter ranging from -1.0 centimeter to 1.1 centimeter. Mean knee range of motion was 137.55 degrees ranging from 118 to 152 degrees. There were no major complications. Five cases had to open to achieve reduction. There were 5 cases of malunion and 8 cases of superficial infections. Detail is elaborated in the table 1 and complications are in table 2. 
Table 2. Complications.

\begin{tabular}{|l|l|}
\hline Complication & No of cases $(\mathbf{n}=\mathbf{4 0})$ \\
\hline malunion & 5 \\
\hline Nonunion & 0 \\
\hline Deep infection & 0 \\
\hline Superficial infection & 8 \\
\hline Nail breakage & 0 \\
\hline Implant revision & 0 \\
\hline
\end{tabular}

\section{DISCUSSION}

Pediatric femoral shaft fractures are conventionally treated by either primary hip spica or skin traction followed by hip spica. Fractures readily unite with some amount of overlapping and angulations which is believed to get corrected by remodeling potentiality in children. ${ }^{13-15}$ This treatment requires prolonged hospitalization or immobility which has raised awareness of the possible social, economic, educational, and emotional burden of prolonged immobilization. ${ }^{5,6,16}$ After publication of good outcomes by the Nancy group in the early 1980s, Elastic Stable Intramedullary Nailing (ESIN) has become a wellaccepted method of surgical treatment of long bone fractures in children and adolescents. ${ }^{9,17}$ Compared to plating, flexible intramedullary nailing of the femoral shaft fractures in patients provides better results. ${ }^{18}$ There are many reasons for this acceptance including absence of postoperative casting in most cases, primary bone union without growth plate injury, rapid recovery of joint motion and return to physical activities, minimally invasive surgery allowing small and aesthetic scars, low infection rate, and shortened hospital stays. ${ }^{19}$ In our series, there was more male as compared to female child which can be explained by the fact that male children are physically more active so get more injuries. Average union time was 12.8 week which is in comparison with the other series. ${ }^{20,21}$ In our series we have found that there was average shortening of $0.16 \mathrm{~cm}$ which is very minimal in other series. This study

\section{REFERENCES}

1. Hinton RY, Lincoln A, Crockett MM, Sponseller P, Smith G. Fractures of the femoral shaft in children. Incidence, mechanisms, and sociodemographic risk factors. J Bone Joint Surg Am. 1999;81:500-9.

2. Buess E, Kaelin A. One hundred pediatric femoral fractures: epidemiology, treatment attitudes, and early complications. J Pediatr Orthop B. 1998;7:186-92.

3. Coyte PC, Bronskill SE, Hirji ZZ, igle-Takacs G, Trerise BS, Wright JG. Economic evaluation of 2 treatments for pediatric femoral shaft fractures. Clin Orthop Relat Res. 1997;336:205-15.

4. Kasser JR. Femur fractures in children. Instr Course Lect. 1992; 41:403-8.

5. Buechsenschuetz KE, Mehlman CT, Shaw KJ, Crawford AH, Immerman EB. Femoral shaft fractures in children: traction and casting versus elastic stable intramedullary nailing. J Trauma. 2002;53:914-21. reveals that there is some amount of shortening in the beginning but later there will be overgrowth. In our series knee range of motion was good in almost all cases except in those cases where there was superficial infection. These superficial infections caused pain and inflammation around knee which may cause reduction in the range of motion. This was recovered after control of infection after removal of nail. We encountered $5(12.5 \%)$ cases of malunion but this malunion did not present any clinical and functional disability. Our rate of malunion is less that other series. ${ }^{22}$

Li et al. provided biomechanical evidence that patients weighing more than 40 to $45 \mathrm{~kg}$ who undergo stabilization of a transverse midshaft femur fracture with ESIN are at risk for loss of reduction in the sagittal and coronal planes. ${ }^{23}$ We believe that remodeling potentiality in children will rectify angulation over period of time as shown in series of Flyn et al. where 20 degree angulation was remodeled to 7 degrees over a period of one year. ${ }^{14}$ In our series we encountered 8 cases of superficial infection which resolves after removal of nail. This problem occurred in our initial cases where the nail was left long. This was protruding under the skin and cause infection. In later cases we used to cut the nail only one centimeter out of bone. Although in literature many complications including osteomyelitis, refracture, asymptomatic proximal nail migration, delayed healing or nonunion were described, in our series we did not encounter such complications. ${ }^{5,24-27}$

Our study has shortcomings such as the limited number of patients, short follow up duration and the lack of a control group. Therefore, further studies are needed involving large number of cases to draw definitive conclusion.

\section{CONCLUSION}

Elastic stable intramedullary nailing is the method of choice for the simple pediatrics fracture shaft of femur, as it is minimally invasive and shows good functional and cosmetic results. Surgical technique is simple and reproducible. It allows short hospital stay and quick recovery from pain and is cast-free.
6. Flynn JM, Luedtke LM, Ganley TJ, Dawson J, Davidson RS, Dormans $\mathrm{JP}$, et al. Comparison of titanium elastic nails with traction and a spica cast to treat femoral fractures in children. J Bone Joint Surg Am. 2004;86-A:770-7.

7. Pérez Sicilia JE, Morote Jurado JL, Corbacho Gironés JM, Hernádez Carbrera JA, González Buendía R. Percutaneous osteosynthesis of forearm shaft fractures in children and adolescents. Rev Esp de Cir Ost 1977;12:321-34.

8. Firica A, Popescu R, Scarlet M, Dimitriu M, Jonescu V. Elastic stable osteosynthesis, a new concept: An experimental study. Rev Chir Orthop 1981;67:82-91.

9. Ligier JN, Metaizeau JP, Prévot J. Closed flexible medullary nailing in pediatric traumatology. Chir Pediatr 1983;24:383-5. 
10. Narayanan UG, Hyman JE, Wainwright AM, Rang M, Alman BA. Complications of elastic stable intramedullary nail fixation of pediatric femoral fractures, and how to avoid them. J Pediatr Orthop. 2004;24:363-9.

11. Sink EL, Gralla J, Repine M. Complications of pediatric femur fractures treated with titanium elastic nails: a comparison of fracture types. J Pediatr Orthop. 2005;25:577-80.

12. Luhmann SJ, Schootman M, Schoenecker PL, Dobbs MB, Gordon JE. Complications of titanium elastic nails for pediatric femoral shaft fractures. J Pediatr Orthop. 2003;23:443-7.

13. Salem KH, Lindemann I, Keppler P.Flexible intramedullary nailing in pediatric lower limb fractures. J Pediatr Orthop. 2006 Jul-Aug; 26(4):505-9.

14. Kasser JR. Femoral shaft fractures. In: Rockwood CA Jr, Wilkins KE, Beaty JE. Fractures in children. Lippincott, Philadelphia, 1996.

15. Carey TP, Galpin RD. Flexible intramedullary nail fixation of pediatric femoral fractures. Clin Orthop. 1996;332:110-11.

16. Wright JG. The treatment of femoral shaft fractures in children: a systematic overview and critical appraisal of the literature. Can J Surg. 2000;43:180-9.

17. Me'taizeau JP. L'oste'osynthe'se de l'enfant: techniques et indications. Rev Chir Orthop. 1983; 69:495-511.

18. Caglar O, Aksoy MC, Yazici M, Surat A. Comparison of compression plate and flexible intramedullary nail fixation in pediatric femoral shaft fractures. J Pediatr Orthop Br. 2006;15:210-14.

19. Lascombes P, Haumont T, Journeau P. Use and abuse of flexible intramedullary nailing in children and adolescents. J Pediatr Orthop. 2006; 26:827-834.
20. Cramer KE1, Tornetta P 3rd, Spero CR, Alter S, Miraliakbar H, Teefey J: Ender rod fixation for femoral shaft fractures in children. Clin orthop. 2000 Jul;(376):119-23.

21. Flyn JM, Schwend RM. Managememt of pediatric femoral shaft fractures. J am acad orthop surg. Sep-oct 2004;12(5):347-59.

22. Eric J. Wall, Viral Jain, Vagmin Vora, Charles T, Mehlman and Alvin H. Crawford Complications of Titanium and Stainless Steel Elastic Nail Fixation of Pediatric femoral fractures. J Bone Joint Surg Am. 2008;90:1305-1313.

23. Li Y, Stabile KJ, Shilt JS. Biomechanical analysis of titanium elastic nail fixation in a pediatric femur fracture model. J Pediatr Orthop 2008;28:874-878.

24. Wall EJ, Jain V, Vora V, et al: Complications of titanium and stainless steel elastic nail fixation of pediatric femoral fractures. J Bone Jt Surg Am 2008;90:1305-1313.

25. Flynn JM, Hresko T, Reynolds RA, Blasier RD, Davidson R, Kasser J, Titanium elastic nails for pediatric femur fractures - a multicenter study of early results with analysis of complications. J Pediatr Orthop. $2001 ; 21: 4-8$.

26. Jubel A, Andermahr J, Isenberg J, Schiffer G, Prokop A, Rehm KE.: Experience with elastic stable intramedullary nailing (ESIN) of shaft fractures in children. Orthopade. 2004;33:928-35.

27. Aksoy MC, Caglar O, Ayvaz M, Yazici M, Alpaslan AM: Treatment of complicated pediatric femoral fractures with titanium elastic nail. $J$ Pediatr Orthop B. 2008;17:7-10. 